\title{
Exendin-4 Alleviates High Glucose-Induced Rat Mesangial Cell Dysfunction through the AMPK Pathway
}

\author{
Wen-Wei Xuab Mei-Ping Guan ${ }^{\mathrm{ab}} \quad$ Zong-Ji Zheng ${ }^{\mathrm{a}} \quad$ Fang Gao ${ }^{\mathrm{a}}$ Yan-Mei Zeng ${ }^{\mathrm{a}}$ \\ Yan Qina Yao-Ming Xue \\ aDepartment of Endocrinology and Metabolism, Nanfang Hospital, Southern Medical University,

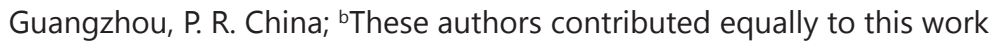

\section{Key Words}

AMPK • Cell proliferation • Fibronectin $・$ ERK $・ \mathrm{mTOR} \cdot \mathrm{MMP}-2 \cdot \mathrm{TIMP}-2$

\begin{abstract}
Background/Aims: Glucagon-like peptide-1 (GLP-1), which counteracts insulin resistance in humans with type 2 diabetes, has been shown to ameliorate diabetic nephropathy in experimental models. However, the mechanisms through which GLP-1 modulates renal function remained illdefined. The present study investigated the putative mechanisms underlying effects of exendin-4, a GLP-1 analog, on mesangial cell proliferation and fibronectin. Methods: Rat mesangial cells (MCs) were treated with exendin-4 under high glucose conditions. AMPactivated protein kinase (AMPK) inhibitors (compound C) and agonists (AICAR) were used to analyze the role of this kinase. Cell proliferation was measured using a MTT assay. Fibronectin expression and AMPK-signaling pathway activity were assessed using ELISA and Western blotting, respectively. The production of matrix metalloproteinase (MMP)-2 and tissue inhibitors of metalloproteinases (TIMP)-2 was evaluated using quantitative real-time RT-PCR. Results: Exendin-4 inhibited cell proliferation and fibronectin secretion in high glucose-induced MCs. It also caused phosphorylation of AMPK and subsequently increased the ratio of MMP-2 to TIMP-2, which resulted in the degradation of fibronectin. Exendin-4 reversed extracellular signal-regulated kinase (ERK) phosphorylation and enhanced expression of mammalian target of rapamycin (mTOR) in MCs. Moreover, the activation of the AMPK pathway by exendin-4 was induced by AICAR, which was inhibited by compound C. Conclusion: Exendin-4 exerts an inhibitory effect on cell proliferation and fibronectin secretion in rat MCs, partly through AMPK activation. These results may explain some of the beneficial effects of exendin- 4 on the kidney.
\end{abstract}

Copyright @ 02014 S. Karger AG, Basel 


\section{Introduction}

Diabetic nephropathy (DN) has been the leading cause of end-stage renal disease in developed countries, while the number of patients with DN is increasing because of the high morbidity of diabetes. Furthermore, DN contributes to an increase of cardiovascular risk and all-cause mortality rates [1]. Therefore, treatment of DN, which improves the prognosis of diabetic patients, warrants further investigation. MC proliferation, extracellular matrix (ECM) accumulation and glomerular basement membrane thickening play important roles in the pathogenesis of DN. Resident and nonresident renal cells stimulated by hyperglycemia produce cytokines, growth factors such as transforming growth factor (TGF)- $\beta 1$ and other mediators that are responsible for structural alterations such as mesangial expansion and increased deposition of ECM proteins [2]. MCs also play a role in the synthesis, as well as the degradation of the ECM, which is mediated by proteinases such as matrix metalloproteinases (MMPs), including type IV collagen, laminin, fibronectin (FN) and proteoglycans $[3,4]$.

MMPs are a large family of zinc-dependent endopeptidases that are collectively capable of degrading all components of the ECM [5]. ECM activity is also regulated by a family of endogenous inhibitors known as tissue inhibitors of metalloproteinases (TIMPs) [6]. Imbalance between MMPs and TIMPs has been implicated in the disruption of ECM homeostasis [7, 8]. The decreasing ratios of MMPs to TIMPs, especially MMP-2 to TIMP-2 and MMP-9 to TIMP-1 may result in augmentation of ECM protein deposition.

ERK1 and ERK2 are related protein-serine/threonine kinases that participate in the RAS/RAF/MEK/ERK signal transduction cascade, which is involved in the regulation of a large variety of processes, including cell cycle progression, cell migration, differentiation, proliferation and transcription $[9,10]$. In vitro studies have confirmed that ERK is activated in high glucose-induced mesangial cells $[11,12]$. The mTOR pathway has a well-established role in cell proliferation; it can be activated by ERK and plays a part in DN [13].

As a GLP-1 receptor agonist, exendin-4 has been clinically used in patients with type 2 diabetes. A previous study demonstrated that exendin-4 ameliorated renal injury without lowering blood glucose levels in a streptozotocin (STZ)-induced rat model, showing that exendin-4 exerted renoprotective effects in blood glucose-level independent pathways [14]. An in vitro study also revealed that exendin-4 inhibited MC multiplication and expression of transforming growth factor- $\beta 1$ and connective tissue growth factor, both of which induced ECM accumulation [15]. Exendin-4 induced phosphorylation of AMPK, which reduced weight gain and insulin resistance in mice with high-fat diets [16]. Additionally, phosphorylated AMPK was down-regulated in the kidneys of $\mathrm{db} / \mathrm{db}$ mice $[17,18]$.

Therefore, the aim of this study was to investigate the effect of exendin- 4 on cell proliferation and ECM expression in MCs and to define the mechanism involved with AMPK pathway activity.

\section{Materials and Methods}

\section{Reagents}

Exendin-4 was purchased from AnaSpec, Inc. AMPK inhibitor (compound C) and AMPK agonist (5-aminoimidazole-4-carboxamide-1 $\beta$-D-ribofuranoside, AICAR) were purchased from Merck Millipore and Cell Signaling Technology, Inc., respectively. 3-(4,5-dimethyl-2 thiazoyl)-2,5-diphenyl-2H-tetrazolium bromide (MTT) was purchased from Merck Millipore.

\section{Cell culture and treatment}

Rat mesangial cell lines (HBZY-1) were routinely maintained in complete DMEM culture medium (Hyclone, Thermo, San Jose, CA), supplemented with $10 \%$ fetal bovine serum (FBS), $100 \mathrm{U} / \mathrm{ml}$ penicillin and $100 \mu \mathrm{g} / \mathrm{ml}$ streptomycin (both from Sigma-Aldrich). The cells were kept at $37{ }^{\circ} \mathrm{C}$ in a humidified 95\% air, $5 \% \mathrm{CO}_{2}$ atmosphere incubator designated as culture at a steady-state condition. The medium was changed every 2 days. Passages 10-15 of the 
Table1. Sequences of primers and annealing temperatures

\begin{tabular}{|c|c|c|c|}
\hline Gene & Primers & $\begin{array}{c}\text { Product size } \\
\text { (bp) }\end{array}$ & $\begin{array}{c}\text { Accession } \\
\text { number }\end{array}$ \\
\hline \multirow[t]{2}{*}{ MMP-2 } & Forward: 5'-ACGGGCCGTACAATCTTCAC-3' & 83 & NM_031054.2 \\
\hline & Reverse: 5'-AGCAGGAGACAGGGTAACCA-3' & & \\
\hline \multirow[t]{2}{*}{ TIMP-2 } & Forward: 5'- TTCTTCACССССТTCCAAGC-3' & 82 & NM_021989.2 \\
\hline & Reverse: 5' - AACAGCGGGAGGGCATAAC-3' & & \\
\hline \multirow[t]{2}{*}{ MMP-9 } & Forward: 5'- GCCTGTGGTTGGTCAGAAGA-3' & 134 & NM_031055.1 \\
\hline & Reverse: 5'- TAAAAGGGCCGGTAAGGTGG-3' & & \\
\hline \multirow[t]{2}{*}{ TIMP-1 } & Forward: 5' - TGAGAAGGGCTACCAGAGCG-3' & 84 & NM_053819.1 \\
\hline & Reverse: 5'- ATCGAGACCCCAAGGTATTGC-3' & & \\
\hline \multirow[t]{2}{*}{ mTOR } & Forward: 5'- GGCCACCGTGTGTGTAAGAA-3' & 143 & NM_019906.1 \\
\hline & Reverse: 5'- GACCCTGCACTGAGATCCTG-3' & & \\
\hline \multirow[t]{2}{*}{$\beta$-actin } & Forward: 5'- GCGAGTACAACCTTCTTGCAG-3' & 115 & NM_031144.3 \\
\hline & Reverse: 5'- GCCTTGCACATGCCGGA-3' & & \\
\hline
\end{tabular}

cells were used in this study. MCs at approximately $80 \%$ confluence were cultured in 1\% FBS DMEN medium for 24 hours for synchronization, and then were exposed to low glucose $(5.6 \mathrm{mM})$, high glucose $(30 \mathrm{mM})$, with or without the additional application of exendin-4 (0.1, $1,10$ or $100 \mathrm{nM})$, Compound C $(10 \mu \mathrm{M})$ or AICAR $(1 \mathrm{mM})$.

Cell proliferation (MTT) assays

MCs were seeded in 96-well flat bottom plates at a density of $4 \times 10^{3}$ cells/well $(200 \mu \mathrm{l} /$ well). After synchronization, cells were treated with different concentrations of the indicated reagent for 24 hours. Medium was then replaced with $20 \mu \mathrm{l} \mathrm{of} 0.01 \mathrm{~mol} / \mathrm{L}$ Phosphate Buffered Saline (PBS) containing MTT ( $5 \mathrm{mg} / \mathrm{ml}$ ). After a $4 \mathrm{~h}$ incubation at $37^{\circ} \mathrm{C}$, MTT-containing PBS was removed, and $150 \mu \mathrm{l}$ of DMSO (Sigma-Aldrich) was added to each well. After gentle mixing for $15 \mathrm{~min}$, the reduced purple formazan crystals were dissolved, and the absorbance was read at $490 \mathrm{~nm}$ using an ELx800 microplate (Bio-tek, Vermont, USA).

\section{ELISA}

Cell culture supernatants from different treatment groups were harvested and centrifuged at $2000 \mathrm{~g}$ for $20 \mathrm{~min}$. After centrifugation, the supernatants were then assayed for TGF- $\beta 1$ and FN using the ELISA kits (Boster Biological Engineering Co., Wuhan, China). The absorbance was read at $450 \mathrm{~nm}$ with an ELx800 microplate (Bio-tek, Vermont, USA).

\section{Quantitative real-time PCR}

Total RNA was extracted from MCs lysed in RNAiso Plus (Takara, Shiga, Japan). The RNA quality was determined using a the NanoDrop ND-1000 spectrophotometer (Thermo Fisher Scientific Inc., MA, USA). Reverse transcription of RNA was carried out according to the instructions of PrimeScript RT Master Mix (Takara, Shiga, Japan). Real-time PCR was conducted with 40 ng of cDNA using an ABI Prism 7500 real-time PCR system (Applied Biosystems, Foster City, CA, USA), and PCR amplifications were performed with the Allin-One qPCR Mix (GeneCopoeia, Guangzhou, China) using primers shown in Table 1. The cycling program consisted of $10 \mathrm{~min}$ at $95^{\circ} \mathrm{C}$, followed by 40 cycles of $95^{\circ} \mathrm{C}$ for $10 \mathrm{~s}, 60^{\circ} \mathrm{C}$ for $20 \mathrm{~s}$, and $72{ }^{\circ} \mathrm{C}$ for $34 \mathrm{~s}$. The reactions were quantified according to the amplification cycles when the PCR products of interest were first detected (threshold cycle, Ct). Each reaction was performed in triplicate. The expression of the transcripts was normalized to the levels of $\beta$-actin in the samples.

\section{Western blot analysis}

Western blotting was used to measure the AMPK and ERK levels in MCs. The antibodies used were as follows: phospho-AMPK $\alpha$ (Thr172) and AMPK $\alpha$ (Cell Signaling Technology, 


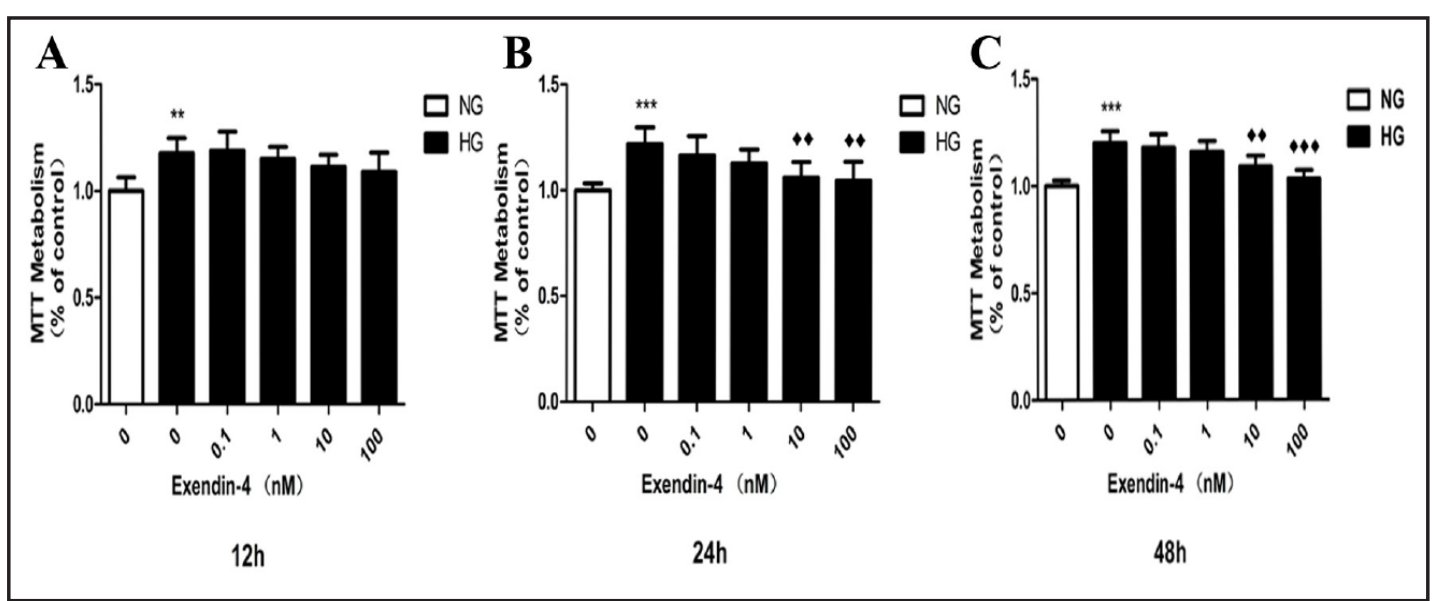

Fig. 1. MTT assay effects of exendin-4 on high glucose-induced MC proliferation. MCs were cultured in DMEM and $5.6 \mathrm{mM}$ glucose (NG) or $30 \mathrm{mM}$ glucose (HG) in the presence of exendin-4 concentrations of 0 (vehicle control), $0.1,1,10$, and $100 \mathrm{nM}$ for 12,24 or 48 hours. Values are the mean \pm SD of six measurements. ${ }^{* *} \mathrm{P}<0.01$ and $^{* * *} \mathrm{P}<0.001$ vs. NG group; $\diamond \mathrm{P}<0.01$ and $\diamond \diamond \mathrm{P}<0.001$ vs. HG group.

Danvers, MA, USA); phospho-p44/42 MAPK (ERK1/2) and p44/42 MAPK (ERK1/2) (Cell Signaling Technology, Danvers, MA, USA). Briefly, the total protein of the MCs was extracted with RIPA Lysis Buffer (Beyotime Institute of Biotechnology, Beijin, China) according to the manufacturer's instructions, which was then subjected to 10\% SDS-PAGE (Bio-Rad Laboratories, Hercules, CA, USA). The separated proteins were transferred to polyvinylidene fluoride membranes (Merck Millipore, MA, USA) by electrotransfer. The membranes were then blocked with Tris-buffered saline with $0.05 \%$ Tween (TBST) and 5\% (wt/vol.) nonfat dry milk, and subsequently immunoblotted with primary antibodies, followed by IRDye 800CW-conjugated secondary antibody (LI-COR, Lincoln, NE). The infrared fluorescence image was obtained using the Odyssey infrared imaging system (LI-COR, Lincoln, NE), and the bands were quantified by Quantity One Version 4.4.0.

\section{Statistical analysis}

Data are presented as the mean \pm SD. Differences between the groups were examined for statistical significance by ANOVA with Bonferroni correction, using SPSS version 13.0. A value of $\mathrm{P}<0.05$ was considered statistically significant.

\section{Results}

Determination of the dose-dependent effect of exendin-4 on MC viability using MTT

MCs cultured in high glucose $(30 \mathrm{mM})$ were used to mimic hyperglycemia in this study because MC proliferation is one of the features of early stage DN. Cell viability was examined by MTT assay to evaluate the effect of exendin-4 on mesangial cells. Cell proliferation was significantly increased in high glucose-cultured MCs relative to the normal glucose $(5.6 \mathrm{mM})$ group. The level of cell proliferation in the high glucose (HG) group increased by $17.5 \pm 7.3 \%$ $(\mathrm{P}=0.001), 21.7 \pm 8.0 \%(\mathrm{P}<0.001)$ and $19.9 \pm 5.7 \%(\mathrm{P}<0.001)$ at 12,24 and 48 h (Fig. 1$)$, respectively. Compared to the high glucose group, the threshold concentration of exendin- 4 that caused decreased MC viability was $10 \mathrm{nM}(106.0 \pm 7.4 \%$ vs. $121.7 \pm 8.0 \%, \mathrm{P}<0.01)$ at 24 hours (Fig. 1B), with maximal effect at $100 \mathrm{nM}(104.4 \pm 9.0 \%$ vs. $121.7 \pm 8.0 \%, \mathrm{P}<0.01)$. Similar results were observed in groups treated for 48 hours $(108.9 \pm 5.0 \%$ vs. $119.9 \pm 5.7 \%$, $\mathrm{P}<0.01 ; 103.2 \pm 4.0 \%$ vs. $119.9 \pm 5.7 \%, \mathrm{P}<0.001$ ) (Fig. 1C). However, exendin -4 seems to have no significant effect on high glucose-induced MCs at 12 hours (Fig. 1A). 

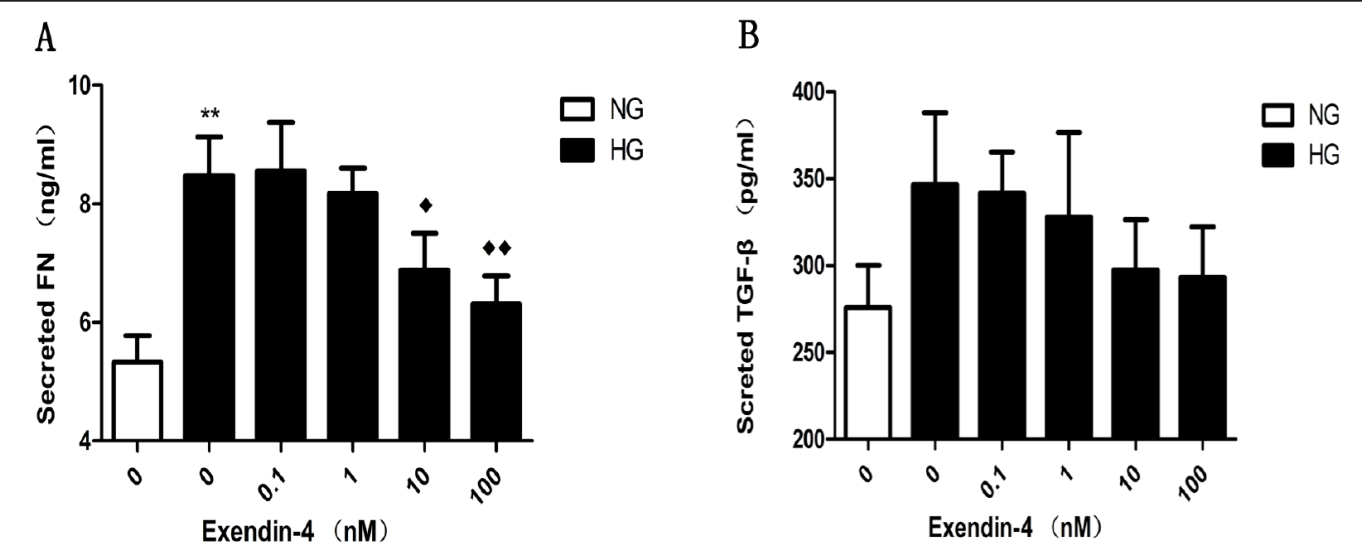

Fig. 2. Expression of FN and TGF- $\beta 1$ in the cell culture supernatants. Supernatants were assayed by ELISA after treatment with different concentration of exendin- 4 for 24 hours. Values are the mean \pm SD of three measurements. ${ }^{* *} \mathrm{P}<0.01$ vs. NG group; $\diamond \mathrm{P}<0.05$ and $\diamond \diamond \mathrm{P}<0.01$ vs. HG group.

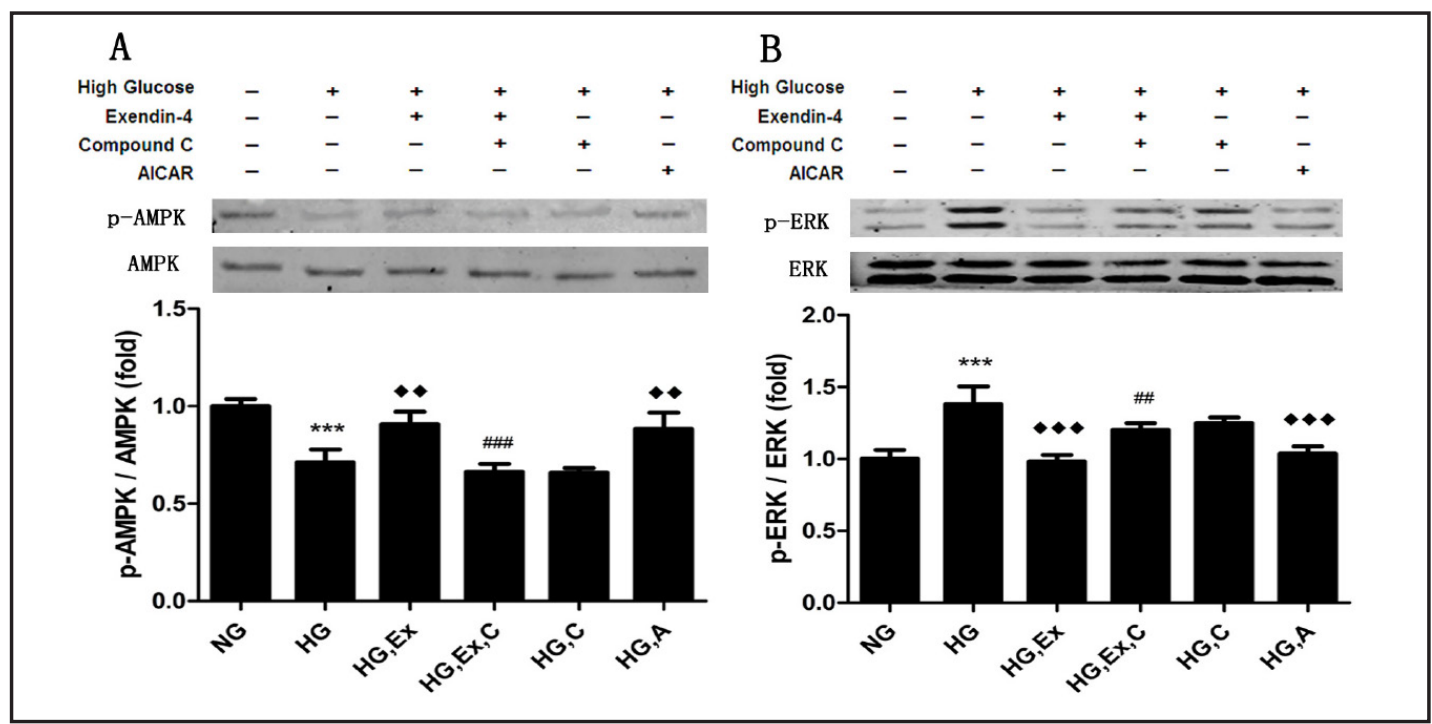

Fig. 3. Effects of exendin-4 on AMPK and ERK activities under high glucose conditions with or without the addition of compound C and AICAR. Ex: exendin-4; C: compound C; A: AICAR. MCs were incubated for $24 \mathrm{~h}$ in the presence or absence of exendin-4 (10 nM). In different groups, cells were treated with compound C (10 $\mu \mathrm{M})$ or AICAR $(1 \mathrm{mM})$ for $1 \mathrm{~h}$ before glucose modulation. Values are the mean \pm SD of four measurements. $* * * \mathrm{P}<0.01$ vs. NG group; $\gg \mathrm{P}<0.01$ and $\diamond \mathrm{P}<0.001$ vs. HG group; \#\#P $<0.01$ and \#\#\# $<0.001$ vs. $\mathrm{HG}+$ Ex group.

\section{Effect of exendin-4 on the secretion of FN in cell culture supernatants}

The production of FN and TGF- $\beta 1$ in cell culture supernatants is summarized in Fig. 2. The secretion of FN was higher from MCs in the high glucose group than in the normal glucose group, whereas expression was down-regulated after treatment with high concentrations (10 nM and $100 \mathrm{nM}$ ) of exendin-4 ( $\mathrm{P}<0.05$ and $\mathrm{P}<0.01$ respectively) (Fig. 2A). Large doses of exendin- 4 also reduced the secretion of TGF- $\beta 1$, however, the change was not statistically significant (Fig. 2B).

Exendin-4 attenuated high glucose-induced phosphorylation of ERK through AMPK signaling

In MCs cultured with high glucose AMPK phosphorylation was inhibited, while AMPK activity was significantly increased by exendin-4 (Fig. 3A). Exendin-4 also reduced the high 


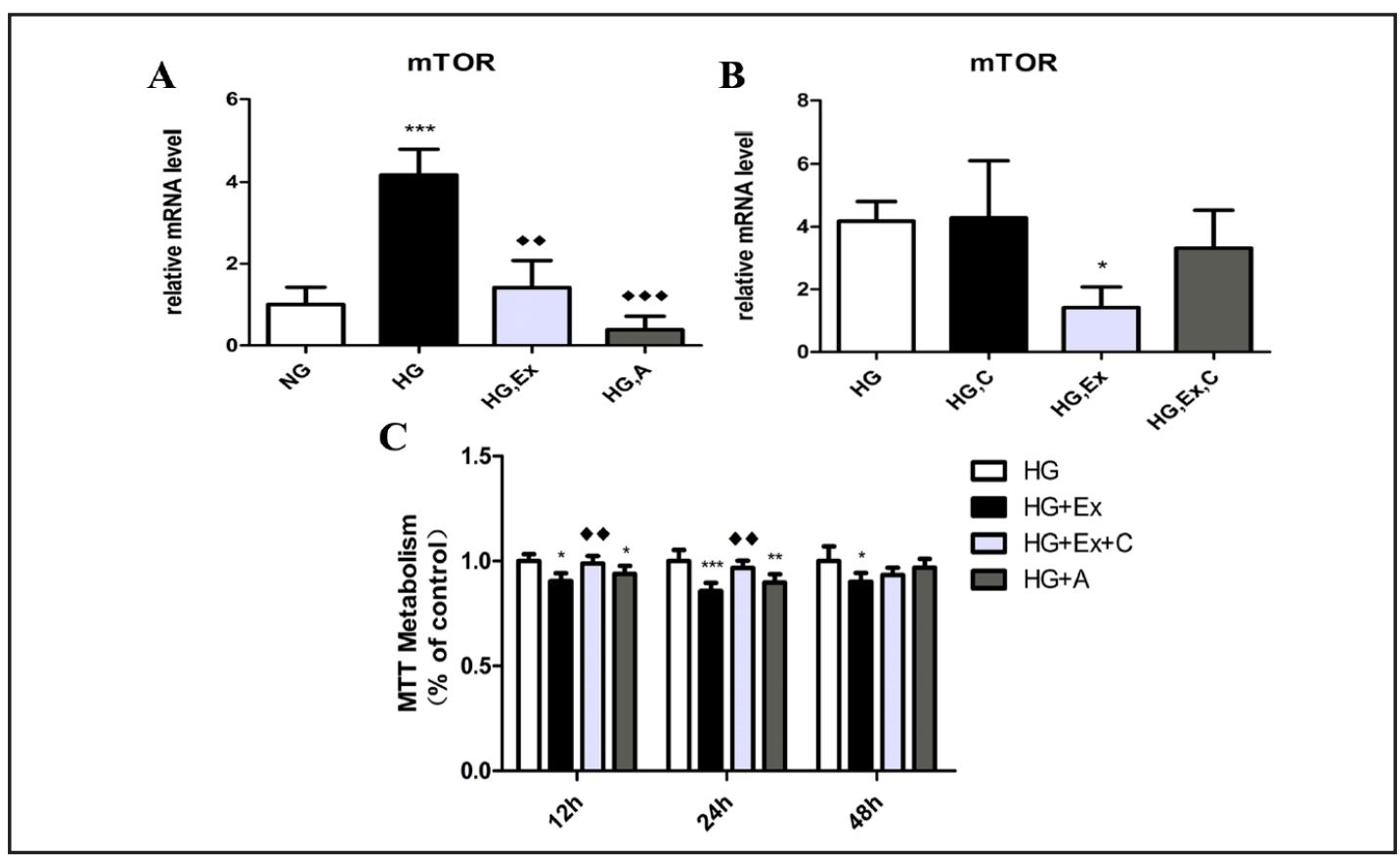

Fig. 4. Regulation of the AMPK pathway affects mTOR exprssion and cell viability. (A) MCs were incubated for $24 \mathrm{~h}$ with normal glucose or high glucose to measure the gene expression of mTOR. Exendin-4 (10 nM) or AICAR ( $1 \mathrm{mM}$ ) were used to assess the effect of AMPK on mTOR mRNA expression. $\mathrm{N}=3$, *** $\mathrm{P}<0.001$ vs. NG group; $>\mathrm{P}<0.01$ and $>\mathrm{P}<0.001$ vs. HG group. (B) The effect of compound $\mathrm{C}(10 \mu \mathrm{M})$ on mTOR mRNA expression was then examined. $\mathrm{N}=3,{ }^{*} \mathrm{P}<0.05$ vs. HG group. (C) Cell viability was also determined in MCs induced by high glucose with the above reagents. $\mathrm{N}=6,{ }^{*} \mathrm{P}<0.05,{ }^{* *} \mathrm{P}<0.01$ and ${ }^{* * *} \mathrm{P}<0.001$ vs. HG group; $>\mathrm{P}<0.01$ vs. HG+Ex group.

glucose-induced phosphorylation of ERK. However, the effects of exendin-4 were attenuated by compound C. AICAR, an AMPK agonist, had a similar effect to exendin-4, decreasing ERK activity (Fig. 3B).

Effects of the regulation of the AMPK signaling pathway on cell proliferation and the expression of $\mathrm{mTOR}$

The mRNA expression of mTOR was up-regulated in the high glucose group relative to the normal glucose group, whereas exendin-4, as well as AICAR, significantly inhibited high glucose-induced expression of mTOR (Fig. 4A). Down-regulation of mTOR mRNA levels by exendin- 4 was attenuated by compound C, though the change was not significant (Fig. 4B). Similar to exendin-4, AICAR had an inhibitory effect on cell proliferation, which could be attenuated by compound C (Fig. 4C).

Effects of AMPK signaling pathway regulated MMP-2/TIMP-2 expression on FN secretion

We examined the mRNA expression levels of MMP-2, MMP-9, TIMP-2 and TIMP-9 in our study. The levels of these genes were inhibited by high glucose, but no significant changes were observed among the high glucose group and the high glucose groups treated with exendin-4 or AICAR (data not show). However, in the group treated with exendin-4, the mRNA expression levels of MMP-2/TIMP-2 were up-regulated (Fig. 5A). The changes of the mRNA levels of MMP-2/TIMP-2 and MMP-9/TIMP-1 by exendin-4 were reversed with the addition of compound $\mathrm{C}$, which increased and decreased the mRNA expression of TIMP-2 and MMP-9, respectively in group co-treatment with high glucose and exendin-4 (Fig. 5BD). Moreover, compound $\mathrm{C}$ attenuated the effect of exendin-4 on FN secretion in cell culture supernatants (Fig. 5E). 
Fig. 5. Expression of MMP-2/TIMP2, MMP-9/TIMP-1 and FN under AMPK pathway regulation. The ratios of MMP-2 to TIMP-2 and MMP-9 to TIMP-1 as well as the secretion of FN were evaluated under AMPK regulation. $(\mathrm{A}, \mathrm{C}) \mathrm{N}=3,{ }^{* *} \mathrm{P}<0.01$ vs. $\mathrm{NG}$ group; $>\mathrm{P}<0.05$ vs. HG group. (B, D) $\mathrm{N}=3, * * \mathrm{P}<0.01$ vs. HG group; $<0.01$ vs. $\mathrm{HG}+\mathrm{Ex}$ group. (E) $\mathrm{N}=3$, $* \mathrm{P}<0.05$ vs. $\mathrm{HG}$ group.

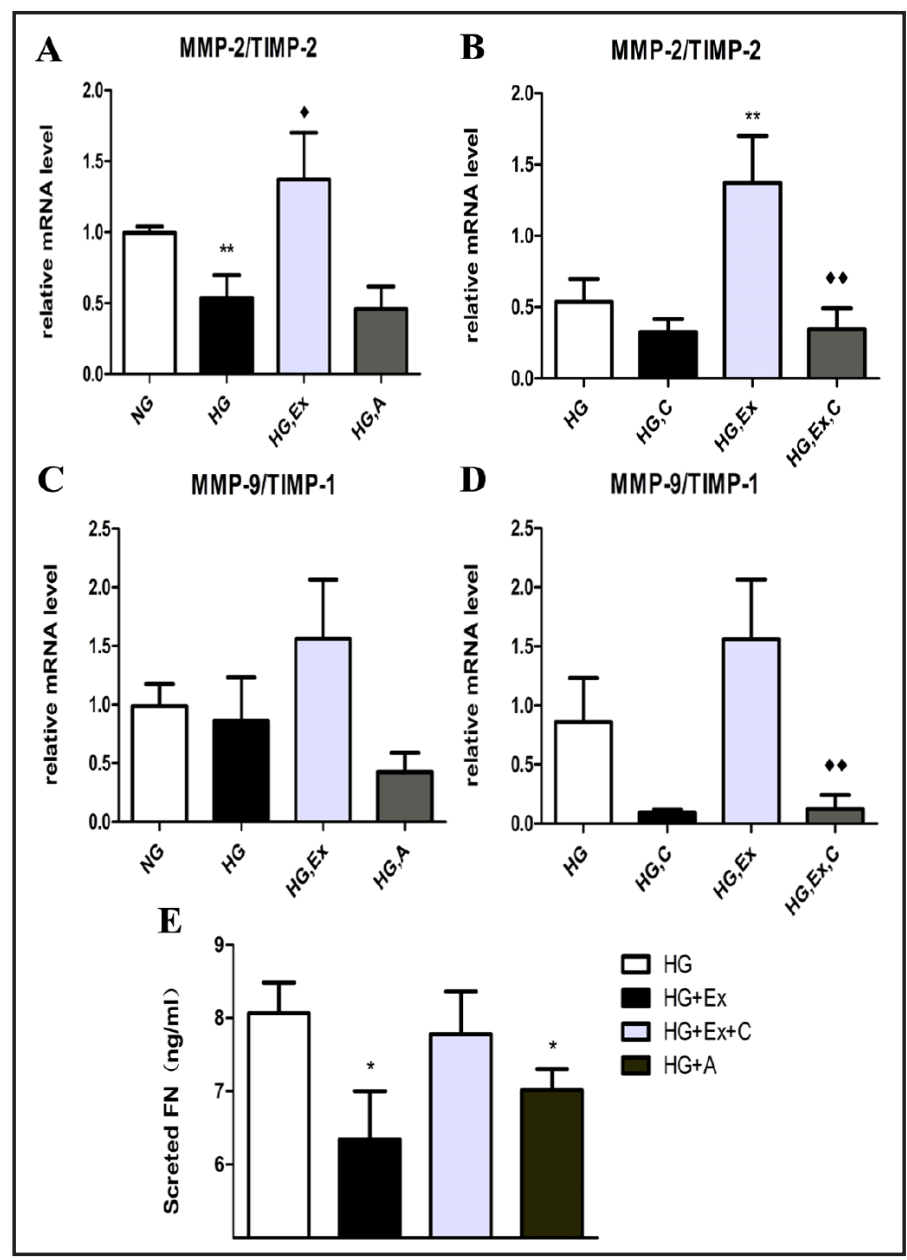

\section{Discussion}

As an incretins, GLP-1 augments glucose-induced insulin release from pancreatic $\beta$-cells and suppresses glucagon secretion through its association with its high-affinity receptor, GLP$1 \mathrm{R}$. GLP-1R is present in extrapancreatic tissues, such as kidneys, vascular tissues and the central nervous system. In vivo studies have shown some functional relevance for its presence in the kidney. However, endogenous GLP-1 is rapidly degraded by dipeptidyl peptidase (DPP)-4, which limits its application. Therefore, GLP-1R agonists that are resistant to DPP-4, such as exendin-4, are currently being used for treating type 2 diabetes. Additionally, these agonist most likely have a beneficial effect on renal function [19]. In STZ-induced diabetic rats, exendin-4 protected against the development and progression of DN by inhibiting the AGE-RAGE-mediated ADMA generation [20]. It also exerted renoprotective effects through its anti-inflammatory action via the GLP-1 receptor, without lowering blood glucose [14]. Correlative studies have shown that exendin- 4 can enhance the phosphorylation of AMPK in the liver of DIO mice and in hepatocytes $[17,21]$, which was down-regulated in the kidneys of $\mathrm{db} / \mathrm{db}$ mice [18]. Initially, AMPK was solely recognized as a highly conserved sensor of cellular energy that regulated $\mathrm{Ca}^{2+}$ and $\mathrm{K}^{+}$channels in different cell types [22, 23]. However, further studies have demonstrated that AMPK also plays a role in the amelioration of epithelial cell damage caused by renal ischemia [24] and cell proliferation through the attenuation of MEK-ERK signaling [25] as well as mTOR activity [26, 27]. Besides, increased AMPK activity downregulates nuclear factor- $\kappa \mathrm{B}$ (NF- $\kappa \mathrm{B})$ signaling which can activate proinflammatory mediators such as TNF- $\alpha$ and promote cell proliferation via SIRT1, peroxisome proliferatoractivated receptor $\gamma$ co-activator $1 \alpha$ (PGC-1 $\alpha$ ), Forkhead box 0 (Fox0) family and p53 [28, 29]. 
In experimental animal models, MC proliferation frequently, precedes and is linked to the increase of ECM in the mesangium and glomerulosclerosis. The proliferation of MCs, which are a part of the glomerular capillaries, can be initiated by basic fibroblast growth factor (bFGF). MC proliferation is maintained by an autocrine mechanism involving platelet-derived growth factor (PDGF). Subsequent development of sclerosis is mediated by TGF- $\beta$ [30]. Reduction of MC proliferation in glomerular disease models by treating with a low-protein diet, heparin or antibodies to PDGF, has been shown to reduce ECM protein deposition and glomerulosclerotic changes [31]. Here, we observed that exendin-4 inhibited MC proliferation in a dose and time-dependent manner according to cell viability assays; in most time course studies, the effective inhibitory concentrations were 10 and $100 \mathrm{nM}$. Exendin-4 also caused AMPK phosphorylation with down-regulation of phospho-ERK and mTOR. However, ERK can also be phosphorylated by the AMPK inhibitor compound $\mathrm{C}$, which increased the expression of mTOR as well. Thus, AMPK activation by exendin-4 could be an upstream effect of ERK phosphorylation and mTOR activation. We also showed that compound $C$ attenuated the inhibitory effect on cell proliferation by exendin-4, and the AMPK agonist AICAR had a similar effect to exendin-4, indicating that the AMPK pathway plays an important role in MC proliferation.

Furthermore, in our experiments the increased expression of FN induced by high glucose was alleviated by exendin-4. As one of the most important ECM proteins, glucose-induced FN expression in MCs results in the accelerated progression of glomerulosclerosis [32]. Therefore, the degradation of FN or other ECM proteins by any means seems to be beneficial in the treatment of DN. Previous studies have implied that MMPs play an important role in regulating physiological homeostasis and pathological disorders of the kidney through modulating the decomposition of ECM components, including FN [6]. As their name implies, the MMP gelatinases, also called MMP-2 and MMP-9, cleave denatured collagen (gelatin) as well as FN in basement membranes [4]. DN has been shown to be associated with decreased expression of MMP-2 and MMP-9 [33,34]. The roles of MMPs in DN seem to vary within different clinical studies. Glomerular MMP-2 expression was decreased in patients with DN compared with normal controls [35]. However, another study showed that increased MMP-9 in plasma precedes the development of microalbuminuria [36].

TIMPs, a family of endogenous, specific inhibitors of MMPs, have varying specificities for different MMPs; for instance, TIMP-2 and TIMP-1 are the specific inhibitors of MMP2 and MMP-9, respectively. Generally, TIMPs combine in a 1:1 stoichiometry with MMPs to cause an inhibitory effect [37]. A recent study suggested a link between an increase in TIMP-2 expression and the activity of STZ-induced diabetic rats [38]. In another study of 35 diabetic patients, TIMP-1 expression was elevated in serum and urine, and urinary TIMP1 levels correlated with increased urine albumin. Nevertheless, circulating TIMP-1 and TIMP-2 are decreased in patients with DN when compared with patients with diabetes [39]. Due to the complexity of MMPs and TIMPs expression levels in DN, the ratios of MMPs to TIMPs may be a more suitable method to evaluate the balance between MMPs and TIMPs. In our study, exendin-4 increased the expression of MMP-2/TIMP-2 induced by high glucose, which could be reversed by compound $\mathrm{C}$, exerting a similar change of FN expression in the culture supernatants. The above results indicate that the inhibitory effect of exendin- 4 on FN secretion, which modulated ECM remodeling, may be regulated through the expression of MMP-2/TIMP-2 via AMPK pathway activation.

In conclusion, our study shows that exendin-4 exerts an inhibitory effect on mesangial cell proliferation under high glucose conditions by decreasing the phosphorylation of ERK and the expression of mTOR, which is partly mediated by AMPK activation. In addition, AMPK phosphorylation induced by exendin-4 modulates the deposition of fibronectin, most likely by regulating the ratio of MMP-2 to TIMP-2. These effects may explain some of the observed renoprotective properties of exendin-4, as well as its beneficial effects on diabetic nephropathy. 


\section{Cellular Physiology Cell Physiol Biochem 2014;33:423-432 and Biochemistry

\section{Conflict of Interest}

The authors declare no conflicts of interest.

\section{Reference}

1 de Zeeuw D, Parving HH, Henning RH: Microalbuminuria as an early marker for cardiovascular disease. J Am Soc Nephrol 2006;17:2100-2105.

2 Schena FP, Gesualdo L: Pathogenetic mechanisms of diabetic nephropathy. J Am Soc Nephrol 2005;16:S3033.

- Caenazzo C, Garbisa S, Onisto M, Zampieri M, Baggio B, Gambaro G: Effect of glucose and heparin on mesangial alpha 1(IV)COLL and MMP-2/TIMP-2 mRNA expression. Nephrol Dial Transplant 1997;12:443448.

4 Tan RJ, Liu Y: Matrix metalloproteinases in kidney homeostasis and diseases. Am J Physiol Renal Physiol 2012;302:F1351-1361

5 Catania JM, Chen G, Parrish AR: Role of matrix metalloproteinases in renal pathophysiologies. Am J Physiol Renal Physiol 2007;292:F905-911.

6 Hopps E, Caimi G: Matrix metalloproteinases in metabolic syndrome. Eur J Intern Med 2012;23:99-104.

7 Tanaka K, Essick EE, Doros G, Tanriverdi K, Connors LH, Seldin DC, Sam F: Circulating matrix metalloproteinases and tissue inhibitors of metalloproteinases in cardiac amyloidosis. J Am Heart Assoc 2013;2:e005868.

-8 Tency I, Verstraelen H, Kroes I, Holtappels G, Verhasselt B, Vaneechoutte M, Verhelst R, Temmerman M: Imbalances between matrix metalloproteinases (MMPs) and tissue inhibitor of metalloproteinases (TIMPs) in maternal serum during preterm labor. PLoS One 2012; 7:e49042.

-9 Dai B, Cui M, Zhu M, Su WL, Qiu MC, Zhang H: STAT1/3 and ERK1/2 Synergistically Regulate Cardiac Fibrosis Induced by High Glucose. Cell Physiol Biochem 2013;32:960-971.

10 Chambard JC, Lefloch R, Pouyssegur J, Lenormand P: ERK implication in cell cycle regulation. Biochim Biophys Acta 2007;1773:1299-1310.

11 Wan-Xin T, Tian-Lei C, Ben W, Wei-Hua W, Ping F: Effect of mitofusin 2 overexpression on the proliferation and apoptosis of high-glucose-induced rat glomerular mesangial cells. J Nephrol 2012;25:1023-1030.

12 Hirasawa Y, Sakai T, Ito M, Yoshimura H, Feng Y, Nagamatsu T: Advanced-glycation-end-productcholesterol-aggregated-protein accelerates the proliferation of mesangial cells mediated by transforminggrowth-factor-beta 1 receptors and the ERK-MAPK pathway. Eur J Pharmacol 2011;672:159-168.

13 Heilig CW, Deb DK, Abdul A, Riaz H, James LR, Salameh J, Nahman NS, Jr.: GLUT1 regulation of the prosclerotic mediators of diabetic nephropathy. Am J Nephrol 2013;38:39-49.

-14 Kodera R, Shikata K, Kataoka HU, Takatsuka T, Miyamoto S, Sasaki M, Kajitani N, Nishishita S, Sarai K, Hirota D, Sato C, Ogawa D, Makino H: Glucagon-like peptide-1 receptor agonist ameliorates renal injury through its anti-inflammatory action without lowering blood glucose level in a rat model of type 1 diabetes. Diabetologia 2011;54:965-978.

15 Li W, Cui M, Wei Y, Kong X, Tang L, Xu D: Inhibition of the expression of TGF-beta1 and CTGF in human mesangial cells by exendin-4, a glucagon-like peptide-1 receptor agonist. Cell Physiol Biochem 2012;30:749-757.

16 Lindegaard B, Matthews VB, Brandt C, Hojman P, Allen TL, Estevez E, Watt MJ, Bruce CR, Mortensen OH, Syberg S, Rudnicka C, Abildgaard J, Pilegaard H, Hidalgo J, Ditlevsen S, Alsted TJ, Madsen AN, Pedersen BK, Febbraio MA: Interleukin-18 activates skeletal muscle AMPK and reduces weight gain and insulin resistance in mice. Diabetes 2013;62:3064-3074.

17 Samson SL, Sathyanarayana P, Jogi M, Gonzalez EV, Gutierrez A, Krishnamurthy R, Muthupillai R, Chan L, Bajaj M: Exenatide decreases hepatic fibroblast growth factor 21 resistance in non-alcoholic fatty liver disease in a mouse model of obesity and in a randomised controlled trial. Diabetologia 2011;54:30933100 .

18 Kim MY, Lim JH, Youn HH, Hong YA, Yang KS, Park HS, Chung S, Ko SH, Shin SJ, Choi BS, Kim HW, Kim YS, Lee JH, Chang YS, Park CW: Resveratrol prevents renal lipotoxicity and inhibits mesangial cell glucotoxicity in a manner dependent on the AMPK-SIRT1-PGC1alpha axis in db/db mice. Diabetologia 2013;56:204-217. 


\section{Cellular Physiology Cell Physiol Biochem 2014;33:423-432 and Biochemistry

19 Filippatos TD, Elisaf MS: Effects of glucagon-like peptide-1 receptor agonists on renal function. World J Diabetes 2013;4:190-201.

20 Ojima A, Ishibashi Y, Matsui T, Maeda S, Nishino Y, Takeuchi M, Fukami K, Yamagishi S: Glucagonlike peptide-1 receptor agonist inhibits asymmetric dimethylarginine generation in the kidney of streptozotocin-induced diabetic rats by blocking advanced glycation end product-induced protein arginine methyltranferase-1 expression. Am J Pathol 2013;182:132-141.

21 Lee J, Hong SW, Chae SW, Kim DH, Choi JH, Bae JC, Park SE, Rhee EJ, Park CY, Oh KW, Park SW, Kim SW, Lee WY: Exendin-4 improves steatohepatitis by increasing Sirt1 expression in high-fat diet-induced obese C57BL/6J mice. PLoS One 2012;7:e31394.

-22 Almilaji A, Munoz C, Elvira B, Fajol A, Pakladok T, Honisch S, Shumilina E, Lang F, Foller M: AMP-activated protein kinase regulates hERG potassium channel. Pflugers Arch 2013;465:1573-1582.

23 Bhavsar SK, Schmidt S, Bobbala D, Nurbaeva MK, Hosseinzadeh Z, Merches K, Fajol A, Wilmes J, Lang F: AMPKalpha1-sensitivity of Orai1 and $\mathrm{Ca}^{2+}$ entry in T - lymphocytes. Cell Physiol Biochem 2013;32:687-698.

24 Seo-Mayer PW, Thulin G, Zhang L, Alves DS, Ardito T, Kashgarian M, Caplan MJ: Preactivation of AMPK by metformin may ameliorate the epithelial cell damage caused by renal ischemia. Am J Physiol Renal Physiol 2011;301:F1346-1357.

-25 Shen CH, Yuan P, Perez-Lorenzo R, Zhang Y, Lee SX, Ou Y, Asara JM, Cantley LC, Zheng B: Phosphorylation of BRAF by AMPK Impairs BRAF-KSR1 Association and Cell Proliferation. Mol Cell 2013;10.1016/j. molcel.2013.08.044

26 Xu J, Ji J, Yan XH: Cross-talk between AMPK and mTOR in regulating energy balance. Crit Rev Food Sci Nutr 2012;52:373-381.

27 Miao XY, Gu ZY, Liu P, Hu Y, Li L, Gong YP, Shu H, Liu Y, Li CL: The human glucagon-like peptide-1 analogue liraglutide regulates pancreatic beta-cell proliferation and apoptosis via an AMPK/mTOR/P70S6K signaling pathway. Peptides 2013;39:71-79.

28 O'Neill LA, Hardie DG: Metabolism of inflammation limited by AMPK and pseudo-starvation. Nature 2013;493:346-355.

29 Salminen A, Hyttinen JM, Kaarniranta K: AMP-activated protein kinase inhibits NF-kappaB signaling and inflammation: impact on healthspan and lifespan. J Mol Med (Berl) 2011;89:667-676.

-30 Couser WG: Pathogenesis of glomerular damage in glomerulonephritis. Nephrol Dial Transplant 1998;13 Suppl 1:10-15.

31 Kurogi Y: Mesangial cell proliferation inhibitors for the treatment of proliferative glomerular disease. Med Res Rev 2003;23:15-31.

-32 Kanwar YS, Sun L, Xie P, Liu FY, Chen S: A glimpse of various pathogenetic mechanisms of diabetic nephropathy. Annu Rev Pathol 2011;6:395-423.

-33 Inada A, Nagai K, Arai H, Miyazaki J, Nomura K, Kanamori H, Toyokuni S, Yamada Y, Bonner-Weir S, Weir GC, Fukatsu A, Seino Y: Establishment of a diabetic mouse model with progressive diabetic nephropathy. Am J Pathol 2005;167:327-336.

-34 McLennan SV, Kelly DJ, Cox AJ, Cao Z, Lyons JG, Yue DK, Gilbert RE: Decreased matrix degradation in diabetic nephropathy: effects of ACE inhibition on the expression and activities of matrix metalloproteinases. Diabetologia 2002;45:268-275.

-35 Del Prete D, Anglani F, Forino M, Ceol M, Fioretto P, Nosadini R, Baggio B, Gambaro G: Down-regulation of glomerular matrix metalloproteinase-2 gene in human NIDDM. Diabetologia 1997;40:1449-1454.

-36 Ebihara I, Nakamura T, Shimada N, Koide H: Increased plasma metalloproteinase-9 concentrations precede development of microalbuminuria in non-insulin-dependent diabetes mellitus. Am J Kidney Dis 1998;32:544-550.

37 Nagase H, Visse R, Murphy G: Structure and function of matrix metalloproteinases and TIMPs. Cardiovasc Res 2006;69:562-573.

-38 Han SY, Jee YH, Han KH, Kang YS, Kim HK, Han JY, Kim YS, Cha DR: An imbalance between matrix metalloproteinase- 2 and tissue inhibitor of matrix metalloproteinase-2 contributes to the development of early diabetic nephropathy. Nephrol Dial Transplant 2006;21:2406-2416.

-39 Rysz J, Banach M, Stolarek RA, Pasnik J, Cialkowska-Rysz A, Koktysz R, Piechota M, Baj Z: Serum matrix metalloproteinases MMP-2 and MMP-9 and metalloproteinase tissue inhibitors TIMP-1 and TIMP-2 in diabetic nephropathy. J Nephrol 2007;20:444-452. 